\title{
Circular RNA: a new biomarker for different types of hypertension
}

\author{
Durairaj Sekar $^{1}$
}

Received: 20 June 2019 / Revised: 1 July 2019 / Accepted: 2 July 2019 / Published online: 17 July 2019

(c) The Japanese Society of Hypertension 2019

In developing and developed countries, hypertension (HTN) is one of the most common, complex non-communicable diseases, and it is caused by many factors, including genetic, environmental, and physiological factors [1]. It has been found that changes in the renin-angiotensin-aldosterone system (RAAS), thrombogenesis, and impaired platelet function also cause HTN, but the exact molecular mechanisms have not been identified, hindering the development of prognostic predictions [2]. This non-communicable disease affects humans and imparts significant cardiovascular and renal risks to patients. Over the past few decades, extensive research has enhanced our understanding of the underlying pathogenesis of HTN [3].

In general, noncoding RNA molecules such as microRNAs, circular RNAs, and long noncoding RNAs have been found to regulate gene expression at the posttranscriptional level by interacting with messenger RNAs, which triggers either the repression or degradation of translation mechanisms [4-6]. This significant event plays a central role in the regulation of gene expression. Figure 1 represents the role of circRNA in the cells. CircRNAs have been recognized as key regulators of HTN, and they play an important role in the development of many diseases. They are readily detected in the blood, serum, urine, semen, and other body fluids [7-9]. From this perspective, understanding the role of noncoding RNAs in various types of HTN is very important, and it will open the door for the discovery or identification of new prognostic, diagnostic, and therapeutic targets for HTN. Most importantly, circRNAs have emerged as potential biomarkers for HTN and other related diseases. Our group has also showed the role of noncoding RNA (microRNA -510) in HTN and preeclampsia (PE) and

Durairaj Sekar

duraimku@gmail.com

1 Dental Research Cell (DRC-BRULAC), Saveetha Dental College and Hospital, Saveetha Institute of Medical and Technical Science (SIMATS), Saveetha University, Chennai 600077, India

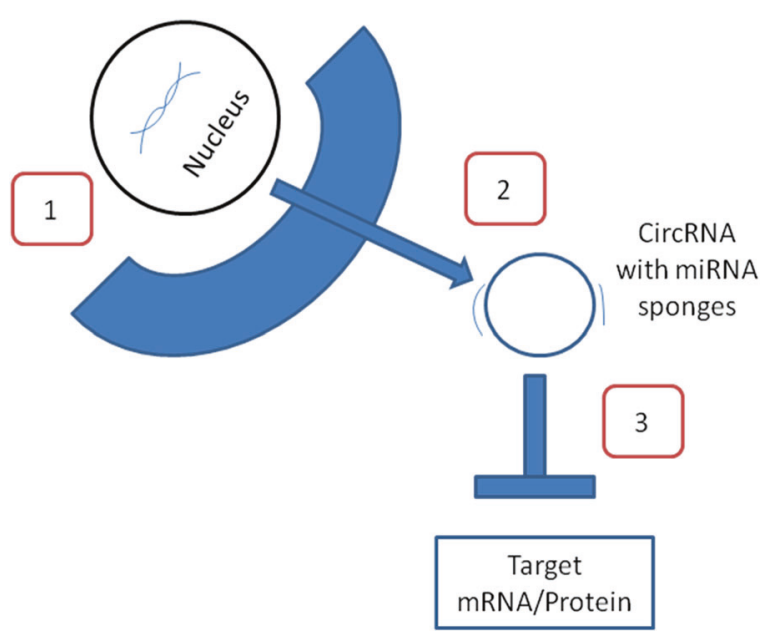

Fig. 1 The role of circular RNAs in the cells. 1. CircRNA originates from the nucleus. 2. CircRNA matures in the cytoplasm. 3. CircRNA with miRNA sponges process and block the target protein/mRNA

how the methylation of miR-510 influences gene expression [10, 11]. Interestingly, an article published in the current edition of Hypertension Research by Mohamed Zaiou has reported the potential impacts of noncoding circRNAs on different types of HTN. An overview of the current research focusing on the emerging role of circRNAs in the pathogenesis of HTN has been described, and some of the challenges encountered by circRNA studies and perspectives on their future directions are also highlighted. The author tries to show that circRNAs are a biomarker for HTN and that understanding their potential role is very important for the development and validation of biomarkers for different types of HTN. More results and clinical data on patients are needed to demonstrate this concept and help define associations of circRNAs in hypertensive patients undergoing different medical treatments. Furthermore, there is no clear molecular mechanism to explain the role of circRNAs, and studies with larger sample sizes will help elucidate the signal transduction pathways that involve circRNAs and their targets in HTN and preeclampsia. 


\section{Compliance with ethical standards}

Conflict of interest The authors declare that they have no conflict of interest.

Publisher's note: Springer Nature remains neutral with regard to jurisdictional claims in published maps and institutional affiliations.

\section{References}

1. Leimena C, Qiu H. Non-coding RNA in the pathogenesis, progression and treatment of hypertension. Int $\mathrm{J}$ Mol Sci. 2018;19:927.

2. Sekar D, Shilpa BR, Das AJ. Relevance of microRNA 21 in different types of hypertension. Curr Hypertens Rep. 2017;19:57.

3. Miao C, Chang J, Zhang G. Recent research progress of microRNAs in hypertension pathogenesis, with a focus on the roles of miRNAs in pulmonary arterial hypertension. Mol Biol Rep. 2018;45:2883-96.

4. Sekar D. Comment on the potential role of microRNAs in hypertension. J Hum Hypertens. 2018;32:639-40.
5. Kontaraki JE, Marketou ME, Zacharis EA, Parthenakis FI, Vardas PE. MicroRNA-9 and microRNA-126 expression levels in patients with essential hypertension:potential markers of targetorgan damage. J Am Soc Hypertens. 2014;8: 368-75.

6. Indolfi C, Iaconetti C, Gareri C, Polimeni A, De Rosa S. Noncoding RNAs in vascular remodeling and restenosis. Vascul Pharmacol. 2019;114:49-63.

7. Kok FO, Baker AH. The function of long non-coding RNAs in vascular biology and disease. Vascul Pharmacol. 2019;114:23-30.

8. Dolinar A, Koritnik B, Glavač D, Ravnik-Glavač M. Circular RNAs as potential blood biomarkers in amyotrophic lateral sclerosis. Mol Neurobiol. 2019. https://doi.org/10.1007/s12035019-1627-X.

9. Li X, Wei Y, Wang Z. microRNA-21 and hypertension. Hypertens Res. 2018;41:649-61.

10. Krishnan R, Mani P, Sivakumar P, Gopinath V, Sekar D. Expression and methylation of circulating microRNA-510 in essential hypertension. Hypertens Res. 2017;40:361-3.

11. Sekar D, Lakshmanan G, Mani P, Biruntha M. Methylationdependent circulating microRNA 510 in preeclampsia patients. Hypertens Res. 2019. https://doi.org/10.1038/s41440019-0269-8. 